\title{
Micro-Bulges Investigation on Laser Modified Tool Steel Surface
}

\author{
Fazliana Fauzun ${ }^{1}$, Syarifah Nur Aqida ${ }^{1,2}$, Izwan Ismail ${ }^{2,3}$ and Norhafzan Bariman ${ }^{1}$ \\ ${ }^{1}$ Faculty of Mechanical Engineering, Universiti Malaysia Pahang, 26600 Pekan Pahang, Malaysia \\ ${ }^{2}$ Automotive Engineering Centre, Universiti Malaysia Pahang, 26600 Pekan Pahang, Malaysia \\ ${ }^{3}$ Faculty of Manufacturing Engineering, Universiti Malaysia Pahang, 26600 Pekan, Malaysia
}

\begin{abstract}
This paper presents micro-bulges investigation on laser modified tool steel. The aim of this study is to understand the effect of laser irradiance and interaction time on surface morphology configuration. An Nd:YAG laser system with TEM 00 pulse processing mode was used to modify the samples. Metallographic study shows samples were analyzed for focal position effect on melted pool size, angle of peaks geometry and laser modified layer depth. Surface morphology were analyzed for surface roughness. Laser modified layer shows depth ranged between 42.22 and $420.12 \mu \mathrm{m}$. Angle of peak bulge was found to be increase with increasing peak power. The maximum roughness, $\mathrm{R}_{\mathrm{a}}$, achieved in modified H13 was $21.10 \mu \mathrm{m}$. These findings are significant to enhance surface properties of laser modified steel and cast iron for dies and high wear resistance applications.
\end{abstract}

\section{Introduction}

In most engineering cases, the designers are responsible to develop surface that have the ability to perform maximum with longer lifespan at the lowest cost. Common problem in most technology systems found to be wear damage which subjected to elevated temperature during operation [1]. Surface topography defined three characteristics of surface finishing which include surface roughness, lay and waviness [2]. Surface modification importance to most industrial applications which are surface dependent such as adhesion, friction, corrosion resistance and wettability [1], [3], [4]. Surface roughness plays an important role in controlling friction and wear between two contact areas during processing [3], [5], [6]. Excessive friction between contact surfaces after thousands cycles during processing produces abundant heat resulted in reduced die lifecycle [1], [7].

In some cases, surface roughness is crucial to enhance adhesion between coating materials and substrate, holding lubricant in machining process and ease component removal from die surface in forming process [1], [5], [8], [9]. Surface texture affects friction by creating resistance that prevented fluid from escaping from surface contact [3], [5]-[7]. Surface topography and structure influenced friction that between contact surfaces. It became one of key which affect the coefficient of friction (COF) especially during transferring film formation in sliding application [3].

Surface texturing known as one best method using laser application. Specified microstructure on laser treated surface were importance to reduce and control friction and wear in most engineering application.
Surface texturing has been applied in mechanical components such as piston rings, thrust rings, sliding bearings, machine tool guide and puncher for friction properties during hot stamping [2].

Various manufacturing process such as machining, grinding, abrasive blasting, milling and electrical discharge machining (EDM) have been introduced to develop surface texture by previous researcher [2], [3], [10], [11]. To date, laser surface texturing became one of the most promising means due to its precision and ability to configure high texture complexity.

Laser melting offers surface properties modification at controlled parameters; energy density, pulse duration, laser spot size and pulse repetition frequency (PRF) [12]-[14]. Intense energy penetration rapidly melted and solidified metal surface for high hardness properties. Most laser processing experimental design prefers pulse mode for a better control the surface integrity. Overlapping pulses, parameters design and material flow behavior affected micro-bulges formation and vary topography of the modified surface [7]. Previous studies found irregularities and mechanical effects resulted from the laser pulses which analyzed by the distribution of residual stress and microhardness on treated surfaces [11]. In order to design most engineering applications, good understanding between mechanical interaction between rough surface become essential [7].

Other than that, laser scanning speed gives crucial relevance in determining surface morphology. Together with high power and high pulse repetition rate, laser scanning speed produced varies machining processes such as texturing, patterning, engraving and structuring could be executed [15]. Nevertheless, the parameters 
need to be processed at sufficient energy to avoid surface vaporization which gives burning effect. In this study, laser surface modification was conducted on AISI H13 tool steel at constant scanning speed, PRF and laser energy. Surface morphology, roughness and micro-bulges formation on laser modified surface were analyzed. The effects of peak power to the surface roughness and angle of micro-bulges were investigated.

\section{Experimental}

Laser surface modification was conducted using a JK300HPS Nd:YAG twin lamp laser source with TEM $_{00}$ mode and $1064 \mathrm{~nm}$ wavelength. A flat AISI H13 tool steel plate of $100 \times 300 \mathrm{~mm}$ dimension was used in asreceived condition. The chemical composition of all materials involved is given in Table 1 . The samples were processed at controlled parameters of peak power $\left(\mathrm{P}_{\mathrm{P}}\right)$ from $1.7 \mathrm{~kW}$ to $2.5 \mathrm{~kW}$, PRF of $50 \mathrm{~Hz}$ and scanning speed $(v)$ of $1000 \mathrm{~mm} / \mathrm{min}$. Three responses investigated were depth of modified surface, surface roughness and angle of micro-bulges.

Table 1. Chemical composition of AISI H13 tool steel.

\begin{tabular}{ccccc}
\hline & $\mathrm{C}$ & $\mathrm{Si}$ & $\mathrm{Mn}$ & $\mathrm{S}$ \\
& $0.401-$ & $0.968-$ & $0.327-$ & $0.0055-$ \\
& 0.473 & 1.000 & 0.343 & 0.0069 \\
\cline { 2 - 5 } & $\mathrm{Co}$ & $\mathrm{Cu}$ & $\mathrm{Ti}$ & $\mathrm{V}$ \\
& $0.0199-$ & $0.08-$ & $0.0094-$ & $0.901-$ \\
& 0.0207 & 0.165 & 0.0123 & 0.927 \\
\cline { 2 - 5 } AISI & $\mathrm{Cr}$ & $\mathrm{Mo}$ & $\mathrm{Ni}$ & $\mathrm{Al}$ \\
$\mathrm{H} 13$ & $4.92-$ & $1.17-$ & $0.073-$ & $0.024-$ \\
steel & 5.03 & 1.24 & 0.107 & 0.046 \\
\cline { 2 - 5 } & $\mathrm{Co}$ & $\mathrm{Cu}$ & $\mathrm{Ti}$ & $\mathrm{V}$ \\
& $0.0199-$ & $0.08-$ & $0.0094-$ & $0.901-$ \\
& 0.0207 & 0.165 & 0.0123 & 0.927 \\
\cline { 2 - 5 } & $\mathrm{W}$ & $\mathrm{Nb}$ & $\mathrm{Fe}$ & \\
& $0.0252-$ & 0.003 & $\mathrm{Balance}$ & \\
& 0.0399 & & & \\
\hline
\end{tabular}

Parameters were set to produce significant amount of energy of $2.0 \mathrm{~J}$ to melt the sample surface. The samples surface was placed perpendicular to the firing direction of laser beam and was linearly translated by $\mathrm{CNC}$ moving control system. The laser processing was assisted by argon gas to avoid surface oxidation. Metallographic study was conducted by IM7000 Series Inverted Optical microscopes. Micro-bulge geometry was designed using computer aided design (CAD) software. Surface roughness was measured by Mitutoyo SURFTEST SJ410 Roughness Tester.

\section{Results and discussion}

The surface cross-sectional micrographs in Table 2 indicate presence of laser modified layer on H13 tool steel substrate with corresponding surface morphology. At constant average power of $100 \mathrm{~W}$ and $2.0 \mathrm{~J}$ laser energy, the surface angle resulted from micro-bulges in micrographs $\mathrm{A}, \mathrm{B}$ and $\mathrm{C}$ increased with increasing peak power. The respective average angle of peak bulge in sample $\mathrm{A}, \mathrm{B}$ and $\mathrm{C}$ was $16^{\circ} 32^{\circ}$ and $36^{\circ}$. Referring to the surface morphology, the micro-bulges direction is determined by linear translation path. The resultant surface roughness was $6.18 \mu \mathrm{m}$, sample $\mathrm{B}$ with $11.39 \mu \mathrm{m}$ while sample $\mathrm{C}$ with $21.10 \mu \mathrm{m}$ as peak power increased from $1.7 \mathrm{~kW}$ to $2.5 \mathrm{~kW}$.

The depth of modified layer also show the same increment pattern from $272.62 \mu \mathrm{m}$ for sample $\mathrm{A}$, while $300.71 \mu \mathrm{m}$ and $338.25 \mu \mathrm{m}$ for sample $\mathrm{B}$ and $\mathrm{C}$ respectively. The increase of angle was due to increase of sample surface temperature at high temperature. This can be seen from laser spot marks diameter from A with 0.62 $\mathrm{mm}$ while $\mathrm{B}$ and $\mathrm{C}$ with 0.64 and $0.68 \mathrm{~mm}$ respectively from the surface morphology. Different directions of laser linear translation affect the bulges pattern formation as shown in micrograph of sample A, B and C in Table 2.

Though laser spot size used was $0.6 \mathrm{~mm}$, a larger diameter was measured on surface morphology of sample $\mathrm{C}$, as high surface temperature extended the melting zone. The higher surface temperature of samples processed at peak power of 2.0 and $2.5 \mathrm{~kW}$ increased molten surface fluidity [12]. High fluidity of molten surface inclined to form micro-bulges when progressing to consequent pulses due to the translation speed of $1000 \mathrm{~mm} / \mathrm{min}$.

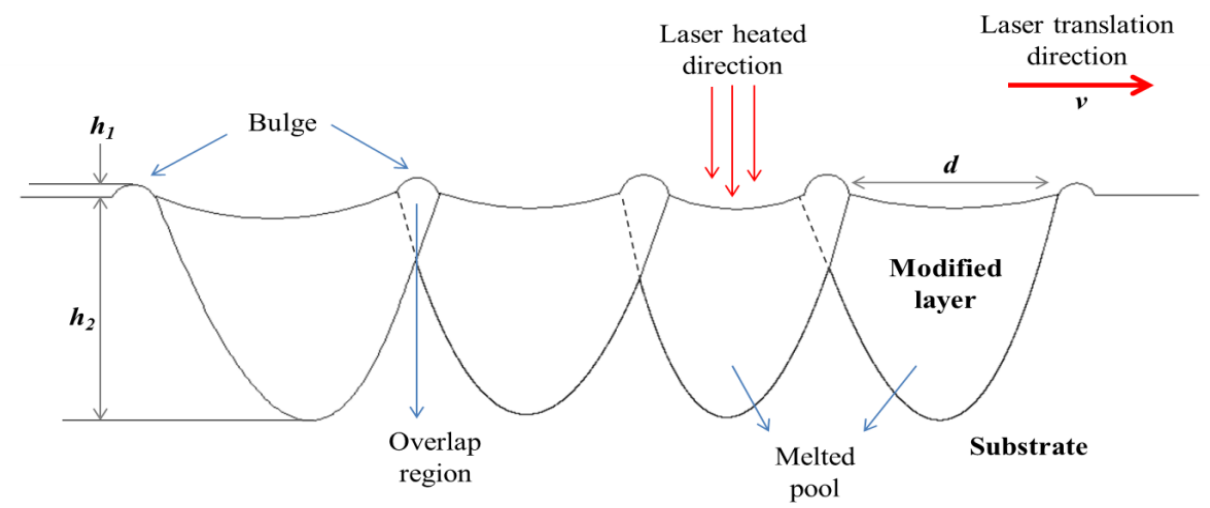

Figure 1. Schematic diagram of the geometrical parameters of laser modified layer. 
Formation of micro-bulges is further explained in schematic diagram of Fig. 1. In laser modified layer of Fig. 1, the height of bulge $\left(h_{1}\right)$, height of melted pool $h_{2}$, diameter $d$ are determined by laser peak power. The melted pool formation processed on a planar surface starts sequentially from one to the end process along the laser translation direction. Increased peak power gives high impact force by the laser power which influence the depth $\left(h_{2}\right)$ and diameter $(d)$ size of melted pool and formation of bulges [11]. The height of bulges was produced by the high recoil pressure transmitted by the laser radiance [2]. Referring to surface morphology of sample A in Table 2, laser impact direction onto the substrate with high power increased the volumetric force on the surface [2]. This phenomenon resulted in increased bulges height as shown in sample $\mathrm{B}$ and $\mathrm{C}$ surface morphology based on darker shading at the spot size edges $(d)$ size of melted pool and formation of bulges [11].

The height of bulges was produced by the high recoil pressure transmitted by the laser radiance [2]. Referring to surface morphology of sample A in Table 2, laser impact direction onto the substrate with high power increased the volumetric force on the surface [2]. This phenomenon resulted in increased bulges height as shown in sample B and C surface morphology based on darker shading at the spot size edges. High scanning speed influence the formation of bulges peak angle direction either in $\mathrm{x}$ or $\mathrm{z}$-axis.

Surface-laser beam interaction time was essential as it determined the surface geometry of laser modified layer.

The factor which influences the interaction between laser and substrate surface found to be material composition, laser energy, frequency and pulse width [9], [12], [14].

Table 2: Micrographs, surface morphology, surface roughness and depth of modified layer at different peak power settings at 1000 $\mathrm{min} / \mathrm{min}$ scanning speed and $50 \mathrm{~Hz}$ PRF.

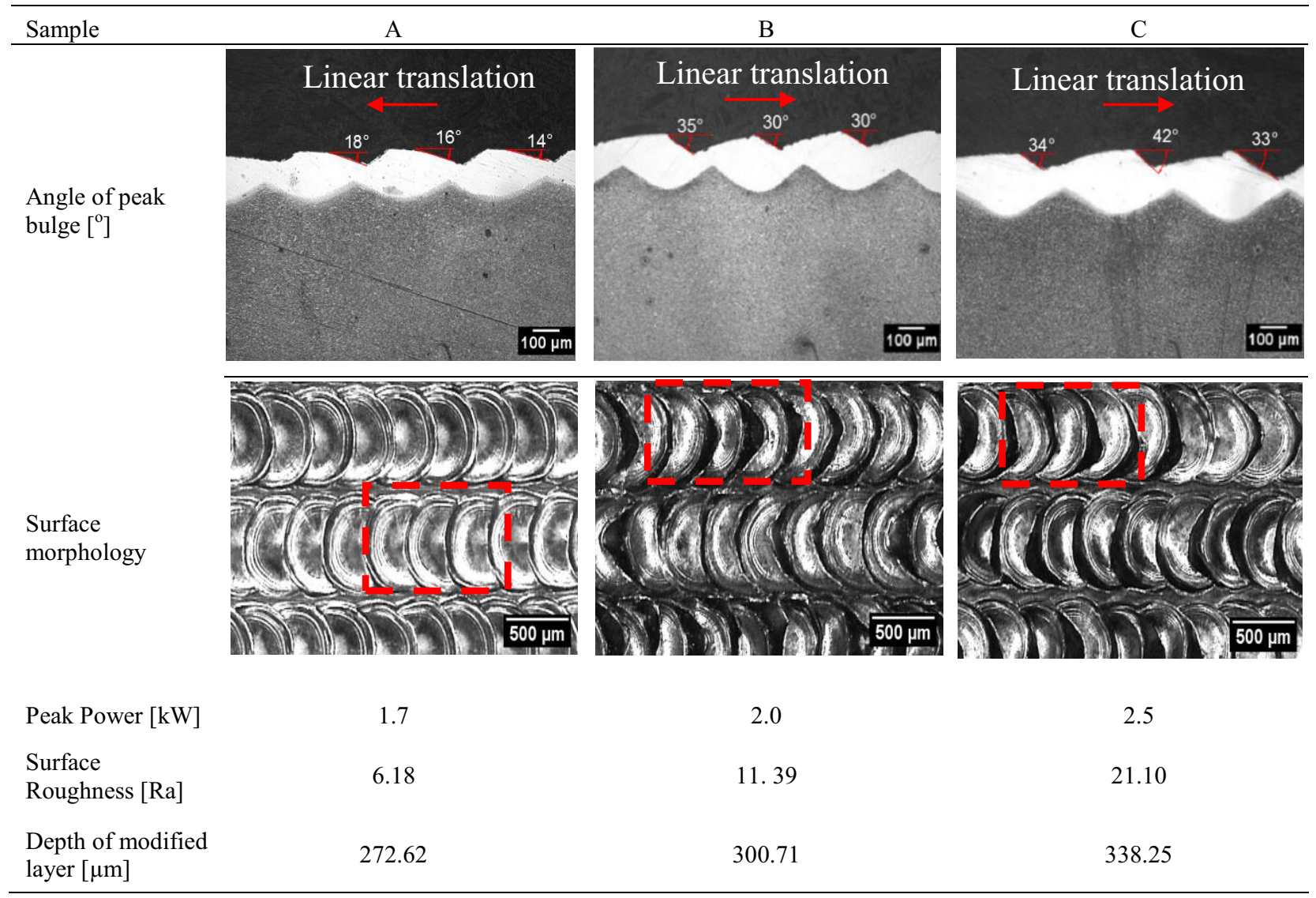

Laser beam generates high strength impact power on the surface thus introduced residual stress. This phenomenon found by previously studies on mechanical effects and regularities due to pulse laser beam [11]. Mechanical response under pulsed laser emitted on processed surface reflected the microscopic surface topography evolution, thus caused the laser frequency to be one of important factor need to be control in order to design surface texture [3], [7], [11]. During laser processing at linear translation, surface material absorbed an amount of energy at from pulse laser that lead to re- melt superficially on overlap region [9]. This is the phenomenon which creates molten pool with bulge on the surface thus influence surface geometry and roughness [2], [7], [13].

\section{Conclusion}

Experimental analysis of three laser modified sample produced an average surface roughness from $6.11 \mu \mathrm{m}$ to 
$21.10 \mu \mathrm{m}$ with average bulges peak angle ranged from $14^{\circ}$ to $42^{\circ}$ concluded followings details:

1. Surface morphology of laser modified H13 tool steel comprised micro-bulges at different angle due to peak power intensity.

2. Laser modified layer depth and angle of bulges were increased with increasing peak power due to higher laser irradiance transmitted into substrate.

3. Average peak power ranged from $1.7 \mathrm{~kW}$ to $2.5 \mathrm{~kW}$ transmitted sufficient amount of energy of $2.0 \mathrm{~J}$ to melt the substrate surface.

4. Laser scanning speed influenced direction of bulge peak angle thus produced vary surface morphology for all samples.

These findings signify preliminary effects of parameter on micro-feature geometry formation using laser processing. Laser surface modification introduced one of the best methods of surface texturing due to its high precision processing.

\section{Acknowledgement}

This work was financially supported by Universiti Malaysia Pahang (Grant no.: RDU1403150).

\section{References}

1. Tomala, A., et al., Tribological performance of some solid lubricants for hot forming through laboratory simulative tests. Tribology International. 74: p. 164173, (2014).

2. Zhou, J., et al., Experimental study on laser microstructures using long pulse. Optics and Lasers in Engineering. 78: p. 113-120, (2016).

3. Menezes, P.L. and S.V. Kailas, Role of surface texture and roughness parameters on friction and transfer film formation when UHMWPE sliding against steel. Biosurface and Biotribology. 2(1): p. 110, (2016).

4. Dunn, A., et al., Laser surface texturing for high friction contacts. Applied Surface Science. 357, Part B: p. 2313-2319, (2015).
5. Vlădescu, S.-C., et al., Combined friction and wear reduction in a reciprocating contact through laser surface texturing. Wear. 358-359: p. 51-61, (2016).

6. Jeong, S.-H., et al., Effects of solid lubricant and laser surface texturing on frictional performance of pulse electric current sintered Al2O3-ZrO2 composites. Ceramics International. 42(6): p. 78307836, (2016).

7. Kalin, M., et al., Comparing surface topography parameters of rough surfaces obtained with spectral moments and deterministic methods. Tribology International. 93, Part A: p. 137-141, (2016).

8. Medvedev, A.E., et al., Effect of bulk microstructure of commercially pure titanium on surface characteristics and fatigue properties after surface modification by sand blasting and acid-etching. Journal of the Mechanical Behavior of Biomedical Materials. 57: p. 55-68, (2016).

9. Viana, R., et al., Laser texturing of substrate of coated tools - Performance during machining and in adhesion tests. Surface and Coatings Technology. 276: p. 485-501, (2015).

10. Kurniawan, R., G. Kiswanto, and T.J. Ko, Microdimple pattern process and orthogonal cutting force analysis of elliptical vibration texturing. International Journal of Machine Tools and Manufacture. 106: p. 127-140, (2016).

11. Lu, G.X., et al., Microscopic surface topography of a wrought superalloy processed by laser shock peening. Vacuum. 130: p. 25-33, (2016).

12. Aqida, S., D. Brabazon, and S. Naher, Atomic diffusion in laser surface modified AISI H13 steel. Applied Physics A. 112(1): p. 139-142, (2013).

13. Fauzun, F., et al. Optimisation of Pulsed Nd: YAG Laser Processing of Gray Cast Iron for Enhanced Surface Properties. in Advanced Materials Research. (2014).

14. Fauzun, F., M. Wahab, and S.N. Aqida, Laser Surface Modification of AISI 1025 Low Carbon Steel Using Pulsed Nd: YAG Laser for Enhance Surface Properties. Key Engineering Materials. 554: p. 596602, (2013).

15. Mincuzzi, G., et al., Extending ultra-short pulse laser texturing over large area. Applied Surface Science. 386: p. 65-71, (2016). 